\title{
Tornalamada Akustik Emisyon ve Motor Akımı Optimizasyonu ve Analizi
}

\author{
Abdullah Aslan ${ }^{1 *}$ \\ 1* Selçuk Üniversitesi, Akşehir Mühendislik ve Mimarlık Fakültesi, Makine Mühendisliği Bölümü, Konya, Türkiye, (ORCID: 0000-0001-8348-3471), \\ aaslan@selcuk.edu.tr
}

(İlk Geliş Tarihi 10 Mart 2021 ve Kabul Tarihi 31 Mayıs 2021)

(DOI: $10.31590 /$ ejosat.894203)

ATIF/REFERENCE: Aslan, A. (2021). Tornalamada Akustik Emisyon ve Motor Akımı Optimizasyonu ve Analizi. Avrupa Bilim ve Teknoloji Dergisi, (25), 50-57.

$\ddot{O} \mathbf{z}$

Tornalamada kesme parametrelerinin optimizasyonu, iş parçasının yüzey kalitesinin, üretim verimliliğinin ve takım ömrünün artırılması için oldukça önemlidir. Endüstriyel uygulamalarda oldukça fazla sayıda malzemenin talaşlı imalat alanında kullanılması sebebiyle bu malzemelerin verimli bir şekilde işlenebilmesi için kesme parametrelerinin optimizasyonu önemlidir. Ancak özellik birbirinden farklı birçok sektörde kritik yük taşıyan parçalarda kullanılan malzemelerin optimizasyonu elzemdir. Bu nedenle, bu çalışma kapsamında 5140 çeliğinin tornalanması için optimum kesme parametreleri belirlenmiştir. Deneyler kuru işleme koşullarında gerçekleştirilmiş olup 2 farklı kesme hızı, talaş derinliği, ilerleme hızı ve yaklaşma açısı incelenmiştir. Kesme parametreleri, akustik emisyon ve akım sensörlerinden alınan verilerle değerlendirilmiş olup optimizasyon tekniği olarak Taguchi yöntemi kullanılmıştır. Ayrıca kesme parametrelerinin akustik emisyon ve akım üzerindeki etkisi incelenmiştir. Sonuçlara göre kesme hızı motor akımı (70.8\%) ve akustik emisyon (89.5\%) üzerinde en etkili parametre olurken, istatistiksel analiz sonuçlarının hem motor akımı (92.5\%) hem de akustik emisyon (95.9\%) için yüksek güven aralığında olduğu görümüştür. Optimizasyon sonuçlarına göre motor akımı ve akustik emisyonu minimum yapacak parametreler sırası ile $\mathrm{v}_{1} \mathrm{f}_{1} \mathrm{~d}_{1} \kappa_{1}$ ve $\mathrm{v}_{1} \mathrm{f}_{1} \mathrm{~d}_{2} \kappa_{2}$ olarak tespit edilmiştir.

Anahtar Kelimeler: Akustik emisyon, Motor Akımı, Optimizasyon, Taguchi

\section{Acoustic Emission and Motor Current Optimization and Analysis in Turning}

\begin{abstract}
Optimization of cutting parameters in turning is very important for increasing the surface quality, production efficiency and tool life of the workpiece. In industrial applications, it is important to make an optimization study for each material because a large number of materials are used in the field of machining. However, the optimization of materials used in parts carrying critical loads in many different sectors is essential. Therefore, in the scope of this study, optimum cutting parameters for turning 5140 steel were determined. The experiments were carried out under dry machining conditions and 2 different cutting speeds, depth of cut, feed rate and approach angle were investigated. The cutting parameters were evaluated with the data obtained from the acoustic emission and flow sensors, and Taguchi method was used as the optimization technique. In addition, the effect of cutting parameters on acoustic emission and current has been investigated. According to the results, while cutting speed was the most influential parameter on engine current (70.8\%) and acoustic emission (89.5\%), statistical analysis results were found to be in a high confidence interval for both motor current $(92.5 \%)$ and acoustic emission (95.9\%). According to the optimization results, the parameters that will minimize the motor current and acoustic emission were determined as $\mathrm{v}_{1} \mathrm{f}_{1} \mathrm{~d}_{1} \kappa_{1}$ and $\mathrm{v}_{1} \mathrm{f}_{1} \mathrm{~d}_{2} \kappa_{2}$, respectively.
\end{abstract}

Keywords: Acoustic emission, Motor Current, Optimization, Taguchi

*Sorumlu Yazar: aaslan@ selcuk.edu.tr 


\section{Giriş}

Gelişmekte olan tüm yenilikçi imalat yöntemlerine (Sap, 2020; Şap, 2021) rağmen talaşlı imalat faaliyetleri halen endüstriyel faaliyetlerin merkezindedir (Salur ve ark., 2021). Endüstriyel faaliyetlerde kullanılan farklı özelliklerdeki sayısız malzemeyi işleyebilmek için kesici takım üreticileri farklı tiplerde ve özelliklerde kesici takımlar üretmektedir. Ancak her bir malzeme için, talaşlı imalatın yapılacağı tezgâha ve talaşlı işleme uygum optimizasyon çalışmasının yapılarak, imalat sürecinin daha verimli hale getirilmesi elzemdir (Salur ve ark., 2019; Acar ve ark., 2021). Çünkü talaşlı imalat süreci, birçok değişkene karşı oldukça duyarlıdır ve bu değişkenler kesici takımın hasara uğraması, takım tutucu hasarı, iş parçasının yüzey kalitesinin düşüşü ve tezgâh iş gücü kaybı gibi maddi kayıplara sebep olabilir (Uzun ve ark., 2018; Uzun ve Usca, 2018; Kuntoğlu ve ark., 2020). Bu durumu önleyebilmek için çeşitli sensörler yardımıyla veri toplanarak işleme parametreleri optimize edilebilir ve böylelikle talaşlı imalat süreci daha verimli bir hale getirilebilir (Aslan ve ark., 2019; Kuntoğlu ve Sağlam, 2019). Talaşlı imalat süreçleri, kesme kuvvetleri, yüzey pürüzlülüğü, akustik emisyon (AE), titreşim, akım sensörü gibi veriler yardımıyla optmize edilerek, o işlem için en uygun kesme parametreleri elde edilebilir (Kuntoğlu ve Sağlam, 2020).

Akustik emisyon (AE), bir malzemedeki mikroyapısal hareketliliğin ve enerji salınımının bir ölçüsüdür. Bir malzemeye kuvvet uygulandığında içerisindeki dislokasyon hareketliliği sebebiyle gerinim oluşur ve bu hareketlilik te AE olarak adlandırılır. Talaşlı imalat açısından bakıldığında AE, tezgâhtan iş parçasını kesmek için iş parçasına verilen enerjinin mikroyapısal bir ölçüsüdür. AE sensörünün oldukça hassas bir sensör olması sebebiyle sensörün tezgâh üzerinde yerleştirileceği yer ve çıkan verilerin analizi noktasında bazı zorluklara sebebiyet verebileceği belirtilse de, bir çok araştırmacı tarafindan kesici takım durumu izleme de en güvenilir sensörlerden birisi olduğu belirtilmiştir.

Chethan ve ark. (2019) tarafindan yapılan çalışmada Nimonic-75 malzemesinin tornalanması esnasında oluşan akustik emisyon sinyallerinin Taguchi yöntemi ile optimizasyonu yapılmıştır. Taguchi L27 dizisinin kullanıldı̆̆ çalışamda kesme, ilerleme hızları ve talaş derinliği 3 farklı seviyede incelenmiştir. AE sinyallerinin değerlendirilmesi neticesinde en yüksek ilerleme hızı değerinin ve en düşük talaş derinliği değerinin en optimum kesme parametreleri olduğu bildirilmiştir. Fadare ve ark. (2012) tarafından yapılan çalışmada akustik emisyon sinyallerinin sadece düşük kesme hızlarında değil yüksek kesme hızlarında da oldukça iyi sonuçlar verdiği ve kesme parametrelerine oldukça duyarlı olduğu, ayrıca takım aşınmasının takibi konusunda da güvenilir sonuçlar verdiği bildirilmiştir. Bir diğer çalışmada, AE sinyallerinin sert malzemlerin tornalanmasında da oldukça iyi sonuçlar verdiği rapor edilmiştir (Tönshoff ve ark., 2000). Bhuiyan ve ark. (2012) tarafindan orta karbonlu çeliklerin torlanması ile ilgili yapılan çalışmada kesme parametrelerinin AE sinaylleri üzerine etkileri incelenmiş ve çalışma neticesinde AE sinyallerinin talaş derinliği ve ilerleme hızı arttıkça arttığı, bildirilmiştir. Chen ve Li (2007) tarafından yapılan çalışmada tornalama esnasında ortaya çıkan akustik emisyon sinyallaeri farklı bir metod yardımıla ayrıştırılarak daha güvenilir hale getirilmiştir. Daha verimli ve stabil hale getirilen AE sinyallerinin takım durumu izlemede çok daha güvenilir sonuçlar verdiği bildirilmiştir. Ayrıca farklı kesici uçların AE sinyallerini nasıl etkilediği de incelenmiştir. AE sinyalleri titreşim gibi diğer sensörlerle beraber adaptif kontrol çalaışmalarında da sıklıkla tercih edilmektedir. Sharma ve ark. (2008) tarafından yapılan FG-15 dökme demirinin 4 farklı kesme hızı, ilerleme hızı ve talaş derinliğinde tornalanması ile ilgili çalışmada, adaptif sinir bulanık çıkarım sistemi (ANFIS) yardımıyla takım durumu izlenmiş ve bu süreçte $\mathrm{AE}$ sinyalleri kullanılmıştır. ANFIS yönteminde AE sinyallerinin kullanılabileceği fakat bir başka sensörle daha sistem desteklenirse çok daha daha güvenilir sonuçlar elde edilebileceği rapor edilmiştir.

Başaltın ve Yaman (2016) tarafından SAE 1030 çeliğinin tornalanması ile ilgili olarak yapılan çalışmada, kesme parametrelerinin $\mathrm{AE}$ üzerine etkileri incelenmiştir. Kesme derinliği sabit tutularak 3 kesme hızı ve 3 ilerleme hızı kullanılmıştır. Çalışma neticesinde kesme hızının artması ile gürültünün azaldığı bildirilmiş ve böylelikle akustik emisyon ile kesme parametrelerinin ilişkilendirilebileceği ayrıca takım aşınmasının da akustik emisyon sesnsörü yardımıyla izlenebileceği belirtilmiştir. Soğuk iş takım çeliklerinin tornlanması ile ilgili yapılan çalışmada (Li, 2002) kesme parametrelerinin optimize edilmesi için tek bir sensör kullanılmıştır (AE). Kesme hızı ve talaş derinliğinin sabit tutulup 4 farklı ilerleme hızının incenlendiği ve ilerleme hızı değeri arttıkça $\mathrm{AE}$ piklerinin azaldığı bildirilmiştir. $\mathrm{Bu}$ durumun talaşların ani plastik deformasyonun kaynaklandığ düşünülmektedir. Kuntoğlu ve ark. (2020) tarafindan yapılan çalışmada dinamometre, titreşim, akustik emisyon, sıcaklık ve motor akımları sensörleri takım durumu izlemek için kullanılmış ve yüzey cevap meodu yardımıyla optimizasyon yapılmıştır. Yapılan optimizasyon neticeisnde \%95,7 güvenilirlik oranı ile AE sensörünün en güvenilir sensör olduğu rapor edilmiştir.

Al-Habaibeh ve Gindy (2000) tarafından yapılan çalışmada AISI 5140 çeliğinin tornalanma maliyetini ve süresini azaltmak için Taguchi optimizasyonu yapılmıştır. Optimizasyon yapabilmek için akustik emisyon, titraşim, akım ve kesme kuvveti sinyalleri toplanarak işlenmiştir. Bir diğer çalışmada akustik emisyon ve kesme kuvveti verilerinin kesici takım aşınmasına etkileri incelenmiş ve takım aşınması yapay sinir ağları (YSA) yöntemi optimize edilmiştir. YSA yönteminin 1045 çeliğinin akustik emisyon ve kesme kuvveti verileri ile optimizasyonun yapılmasında elverişli olduğu ve düşük hata oranları ile kesme parametrelerinin optimzie edilebileceği bildirilmiştir (Jemielniak ve ark., 1998). Ahmed ve ark. (2019) tarafından paslanmaz çeliklerin tornalanması ile ilgili yapılan çalışmada, takım aşınması ve takım ömrü lineer olmayan regresyon analizi yardımıyla tahmin edilmiştir. Akustik emisyon verileri anlık olarak ölçülerek takım ömrü tahmininde giriş verisi olarak kullanılmş ve AE verilerinin takım durumu izlemede kesme kuvvetleri kadar güvenilir olduğu bildirilmiştir. Bir diğer çalışamda, takım aşınması ile AE arasında doğrudan bir ilişki olduğu, takım aşınması arttıkça AE piklerinin de arttığı rapor edilmiştir (Bhuiyan ve ark., 2016).

Akım sensörü, diğer sensörlere kıyasla talaşlı imalatta takım durumu izleme konusunda daha az tercih edilen bir sensör olsa da kullanımının pratikliği, veri alımının kolaylığı ve bazı durumlarda oldukça iyi sonuçlar vermesi sebebiyle daha çok tercih edilmesi gereken bir sensördür. Özellikle diğer sensör verilerini destekleyici bir sensör olarak da tercih edilebilir.Li (2005) tarafından yapılan çalışmada pahalı bir sensör olan dinamometre yerine akım sensörünün kullanılıp kullanılamayacağı incelenmiş ve akım sensörü yardımıyla teğetsel, eksenel ve radyal kesme kuvvetlerinin \%10, 5 ve 25 
hata oranları ile tahmin edilebileceği bildirilmiştir. Bir çalışmada akım sensörü, AE ve titreşim sensörlerini destekleyici bir sensör olarak kullanılmıştır (Al-Habaibeh ve Gindy, 2000). Talaşlı işleme esnasında takım aşınmasının artışına bağlı olarak hem $\mathrm{AE}$ sinyallerinin hem de motor akımı sinyallerinin arttığı ve buna bağlı olarak takım dumunun takip edileceği bildirilmiştir (Pimenov ve ark., 2019). 5140 çeliklerinin tornalanması ile ilgili yapılan çalışmada akım sensörünün \%74,6 güvenilirlik oranı ile kullanılabileceği bildirilmiştir (Kuntoğlu ve ark., 2020).

Yapılan literatür araştırması göstermektedir ki en temel talaşlı imalat yöntemi olan tornalama da kesme parametrelerinin optimizasyonu ve kesici takımların anlık olarak takip edilmesi oldukça önemlidir. Böylelikle bir tarafdan tüm talaşlı imalat sürecinin verimi artarken diğer yandan arzu edilen kalitede iş parçası elde edilebilir. Sürecin takibi için birçok sensörün kullanılabileceği literatür özetinde görülmektedir. Ancak diğer sensötlere kıyasla daha az tercih edilen akım sensörünün de kesme parametrelerinin optimizasyonunda kullanılabileceğini göstermek adına bu çalışma yapılmıştır.

Literatürdeki bu boşluğu doldurmak adına, bu çalışmada otomotiv sektöründen havacılık sektörüne kadar birçok alanda sıklıkla tercih edilen AISI 5140 çeliğinin tornalanması esnasında kesme hızı, ilerleme, talaş derinliği ve yaklaşma açısının AE sinyalleri ve akım sensörü sinyalleri ile optimizasyonu yapılmıştır. Optimizasyon metodu olarak Taguchi yöntemi kullanımış ayrıca istatistiksel analiz için ANOVA tercih edilmiştir. Sonuçlar, talaşlı imalatta yaygın olarak kullanılan iki sensör verisine ait detaylı analiz ve optimum parametre seçimi için bir rehber görevi görmesi bakımından önem kazanmaktadır.

\section{Materyal ve Metot}

Çalışma kapsamında, orta karbonlu AISI 5140 çeliği kullanılmıştır. Otomotiv sektöründen inşaat sektörüne kadar bir çok alanda kullanılması ve buna bağlı olarak talaşlı imalata tabi tutulması sebebiyle bu malzeme tercih edilmiştir. Kullanılan malzemeler $80 \mathrm{~mm}$ çapında ve $400 \mathrm{~mm}$ uzunluğundadır. 5140 çeliği kullanım alanına göe farklı ısıl işlemlere maruz kalarak arzu edilen mekanik özelliklerin kazandırılabileceği bir malzemedir. Bu çalışmada ise $32 \pm 4 \mathrm{HRC}$ sertlik değerine sahip bir 5140 çeliği seçilmiştir. Herbir deney için aynı geometride tek bir iş parçası kullanılarak elde edilen verilerin güvenilirliği artırılmıştır. Her bir iş parçasından ise 3 paso talaş kaldırılmıştır (yüzey tornalama). Kullanılan malzemenin kimyasal kompozisyonu Tablo 1 de gösterilmektedir.

Talaş kaldırmak için BOEHLERIT TCMT 16T304-P25 kodlu kesici uç kullanılmıştır. Kesici uçlar her bir deney için 1 adet kullanılacak şekilde tamamlanmıştır. Tornalama işlemi De Lorenzo S547-8899 kodlu universal torna tezgahı kullanılmıştır ve deneyler kuru tornalama şartlarında gerçekleştirilmiştir. Deneysel tasarım "tam faktöriyel deney tasarım prensibi" dikkate alınarak yapılmıştır. Çalişmada kesme derinliği (mm) kesme hızı $(\mathrm{m} / \mathrm{dk})$ ve kesme kenarı açısı $\left(^{\circ}\right)$ ikişer seviye olarak seçilmiş ve bu seviyelere ait değerler Tablo 2'de gösterilmiştir.

Tablo 1. 5140 Çeliğinin kimyasal kompozisyonu

\begin{tabular}{c|c|c|c|c|c}
\hline $\mathbf{C}$ & $\mathbf{C r}$ & $\mathbf{S i}$ & $\mathbf{M n}$ & Pmax & Smax \\
\hline $0.38-0.45$ & $0.38-0.45$ & $0.15-0.4$ & $0.6-0.9$ & 0.03 & 0.035 \\
\hline
\end{tabular}

Tablo 2. Tornalamada kullanılan kesme parametreleri ve değerleri

\begin{tabular}{c|c|c|c}
\hline Sembol & Parametreler & Seviye 1 & Seviye 2 \\
\hline$\kappa$ & Yaklaşma Açısı $\left(^{\circ}\right)$ & 90 & 60 \\
\hline $\mathrm{v}$ & Kesme Hızı $(\mathrm{m} / \mathrm{dk})$ & 500 & 350 \\
\hline $\mathrm{f}$ & İlerleme Hızı $(\mathrm{mm} / \mathrm{dev})$ & 0.1 & 0.06 \\
\hline $\mathrm{d}$ & Talaş derinliği $(\mathrm{mm})$ & 2 & 1.5 \\
\hline
\end{tabular}

Akustik emisyon ölçümleri için Kistler 8152B111Switzerland kodlu akustik emisyon sensörü kullanılmıștır ve bu sensör ile $50-400 \mathrm{kHz}$ aralığında ölçüm yapılabilmektedir. Sensör, ölçülen sinyallerin güvenilirliğini artırmak için kesici takımın hemen yanına yerleştirilmiştir. Sensör dış ortam gürültülerini izole piezoelektrik algilma prensibi ile çalışmaktadır. Sensörden alınan veriler veri toplama kartı vasitasıyla toplanarak bilgisayara aktarılıp bilgisayar ortamında değerlendirilmekteidr. Buna ek olarak verilerin akatarımı sürecinde Kistler 5125 kodlu kuplör ve Saintech 3003 güç kaynağı da yardımcı olarak kullanılmıştır.

Motor akımı ölçümleri Weidmüller WAS2 CMA 5/10A kodlu akım sensörü kullanılmıştır. Akım sensöründen alınan veriler aktarım kablosu ile veri kartında toplanıp bilgisayar ortamına gönderilmiştir. Akım sensörü, tezgaha giden ana akım kablosuna yerleştirilmiştir. Sensör aralık etkisi prensibine göre çalışmakta olup aktarım kablosu etrafında oluşan manyetik alanın ve gerilimin ölçülmesi esasına dayanmaktadır.

Sensörlerden toplanan veriler öncelikle bir veri toplama kartına (National Instruments USB-6003) aktarılmış, daha sonra veri işlemek için bir yazılım programı arayüzünde (Signal Express) gürültü giderme, ortalama alma (Sigview) ve kaydedilme işlemleri gerçekleştirilmiştir. Çalışmada kullanılan sensörler ve izlenen adımlar Şekil 1 de'ki akış diyagramında tarif edilmektedir.

Optimizasyon, mühendislik problemlerinin çözümünde oldukça sık kullanılan ve bir kalite karakteristiği için en iyi parametrelerin elde edilmesini sağlayan bir yaklaşımdır. $\mathrm{Bu}$ çalışmada akustik emisyon ve motor akımı kalite karakteristikleri olarak belirlenmiş, tornalama kesme parametrelerinin yanısıra takım geometrisini temsilen yaklaşma açısı optimizasyonu yapılmıştır. Bu maksatla Taguchi sinyal gürültü oranı kullanılmıştır. Taguchi yöntemi bilhassa talaşlı imalatta kullanıma oldukça elverişli olan ve güvenilir sonuçlar veren bir yöntem olarak ön plana çıkmaktadır.

İstatistiksel analiz bir deneysel sonuç üzerinde girdi parametrelerinin ne oranda etkili olduğunu gösteren ve bu bakımdan karmaşık talaşlı imalat işlemlerinde sıklıkla tercih edilen bir yöntem olarak öne çıkmaktadır. Varyans analizi ise çeşitli istatistiksel hesaplamaları içerisinde barındıran bir yöntem olarak sıklıkla kullanılmaktadır. Farklı hesaplama yöntemleri analizin içerisinde değerlendirilerek karşılaştırma yapılması ve elde edilen sonuçların teyit edilmesi mümkün olmaktadır. 


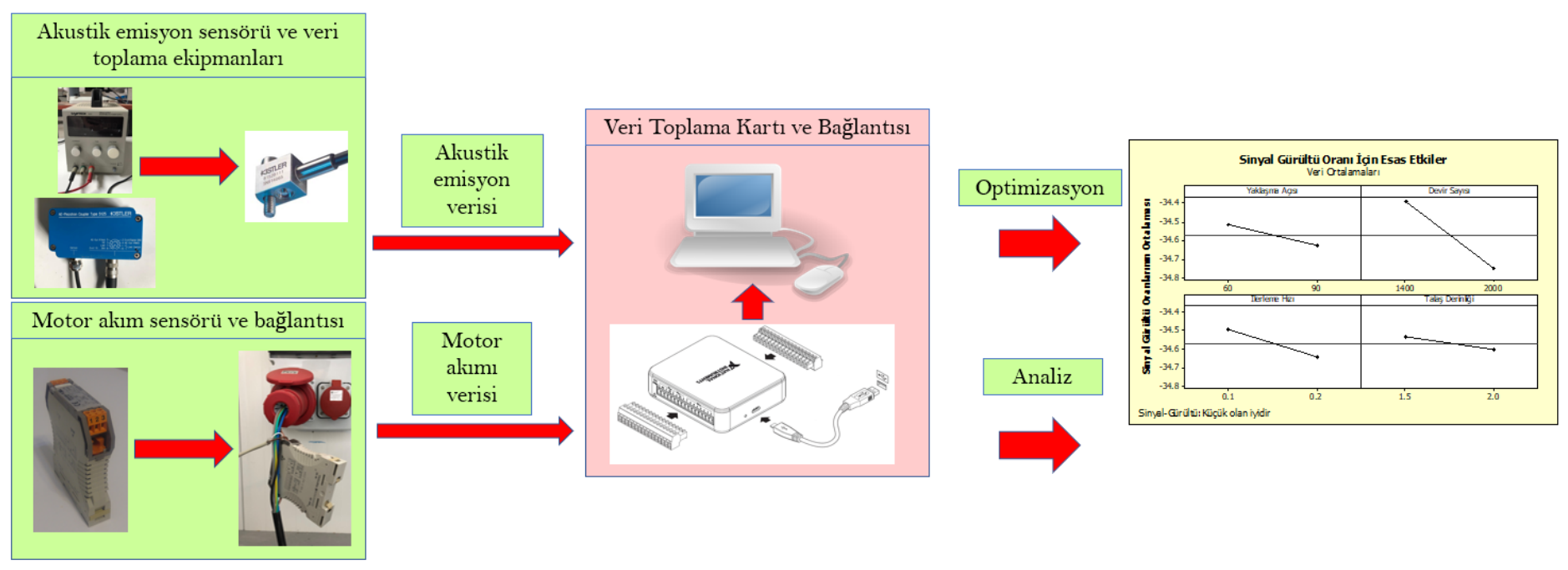

Şekil 1. Deneysel çalışmanın akış diyagramı

Tablo 3.Kesme parametreleri ve elde edilen sonuçlar

\begin{tabular}{ccccccc}
\hline Deney No / Parametre & $\begin{array}{c}\text { Yaklaşma } \\
\text { Açısı }\end{array}$ & $\begin{array}{c}\text { Devir } \\
\text { Sayısı }\end{array}$ & $\begin{array}{c}\text { İlerleme } \\
\text { Hızı }\end{array}$ & $\begin{array}{c}\text { Talaş } \\
\text { Derinliği }\end{array}$ & $\begin{array}{c}\text { Akım } \\
(\mathbf{H z})\end{array}$ & $\begin{array}{c}\text { Akustik } \\
\text { Emisyon (kHz) }\end{array}$ \\
\hline $\mathbf{1}$ & 90 & 2000 & 0.2 & 2 & 55.12 & 71.56 \\
\hline $\mathbf{2}$ & 90 & 2000 & 0.2 & 1.5 & 54.91 & 69.56 \\
\hline $\mathbf{3}$ & 90 & 2000 & 0.1 & 2 & 54.87 & 65.77 \\
\hline $\mathbf{4}$ & 90 & 2000 & 0.1 & 1.5 & 54.66 & 66.74 \\
\hline $\mathbf{5}$ & 90 & 1400 & 0.2 & 2 & 54.1 & 54.87 \\
\hline $\mathbf{6}$ & 90 & 1400 & 0.2 & 1.5 & 53.15 & 56.12 \\
\hline $\mathbf{7}$ & 90 & 1400 & 0.1 & 2 & 52.14 & 55.11 \\
\hline $\mathbf{8}$ & 90 & 1400 & 0.1 & 1.5 & 52.11 & 51.93 \\
\hline $\mathbf{9}$ & 60 & 2000 & 0.2 & 2 & 55.1 & 70.23 \\
\hline $\mathbf{1 0}$ & 60 & 2000 & 0.2 & 1.5 & 54.81 & 68.49 \\
\hline $\mathbf{1 1}$ & 60 & 2000 & 0.1 & 2 & 54.55 & 64.82 \\
\hline $\mathbf{1 2}$ & 60 & 2000 & 0.1 & 1.5 & 53.15 & 68.97 \\
\hline $\mathbf{1 3}$ & 60 & 1400 & 0.2 & 2 & 52.66 & 56.84 \\
\hline $\mathbf{1 4}$ & 60 & 1400 & 0.2 & 1.5 & 52.11 & 58.63 \\
\hline $\mathbf{1 5}$ & 60 & 1400 & 0.1 & 2 & 51.39 & 51.13 \\
\hline $\mathbf{1 6}$ & 60 & 1400 & 0.1 & 1.5 & 51.73 & 53.87 \\
\hline
\end{tabular}

\section{Araştırma Sonuçları ve Tartışma}

Araştırma sonuçlarının detaylı analizi ve optimizasyonu literatürdeki çalışmalarla kıyaslanması ve gelecekteki çalışmalara ışı tutması bakımından önem kazanmaktadır. Bu bölümde elde edilen sensör verilerinin parametre optimizasyonu ve istatistiksel analizi ayr1 ayr1 incelenecektir. Tablo 3'te kesme parametreleri ve elde edilen sonuçlar gösterilmektedir.

\subsection{Motor Akımı Analizi ve Optimizasyonu}

Motor akımı talaşlı imalatta takım tezgahlarının ana millerinin işlevini yerine getirebilmesi için gerekli enerjiyi sağlayan motordan geçen akımı ifade etmektedir. Diğer imalat yöntemleri ile kıyaslandığında güç tüketiminin çok fazla olduğu gözlenen talaşlı imalatta motor akımının tespit edilmesi güç tüketimini ve dolayısı ile maliyeti hesaplama noktasında büyük önem arz etmektedir. Günümüzde popülerliğini artıran sürdürülebilir imalat için göz önünde bulundurulması gereken olmazsa olmaz faktörlerden birisi güç tüketimidir. Bu bakımdan 
motora akımının belirlenmesi ve optimize edilmesi imalat sektörüne ciddi katkı sağlayacaktır (Kuntoğlu ve ark., 2020).

$\mathrm{Bu}$ çalışmada tornalama esnasında anlık olarak ölçülen motor akımı işleme süresince kaydedilmiş olup, daha sonra analizi ve optimizasyonu gerçekleştirilmiştir. Tablo 4, tornalamada kesme parametreleri ve yaklaşma açısının motor akımı üzerindeki katkılarını göstermektedir. SD, serbestlik derecesidir. KT, kareler toplamı anlamına gelir. Her bir kesme parametresinin KT üzerinde etkisi vardır. OK, ortalama kareler anlamına gelir ve KT değerlerinin serbestlik derecesi değerlerine bölünmesi ile bulunur. F-değeri $\mathrm{OK}$ değerleinin ortalama kare hata değerine bölünmesi ile elde edilir. Yüksek bir F değeri, o parametrenin etkinliğinin yüksek olduğunu gösterir. $\mathrm{P}$ değeri deneysel güvenilirlik ile ilgili bir değerdir ve 0,05 in altında olması güvenli olduğunu göstermektedir Yüzde katkı değeri her bir parametreye ait kareler toplamı değerinin toplam değere bölünmesi ile bulunmaktadır. Buradan hareketle devir sayısının motor akımı üzerinde en etkili parametre olduğu görülmektedir. Devir sayısı özellikle tornalama işleminde talaş kaldırma işleminin gerçekleştirilebilmesi için iş parçasına gerekli enerjiyi sağlayan parametre olarak bilinmektedir. Devir sayısının artması, kesme sicaklıklarını artıracağından malzeme deformasyonunu kolaylaştırır (Aslan, 2020; Kuntoğlu ve ark., 2021). Klasik bir tornalama işleminde talaş kaldırmayı sağlayan esas hareket olan iş parçası devri, bu vesileyle hareketi ileten motor üzerinde en yüksek akımın oluşmasına sebep olmaktadır (Kuntoğlu ve Aslan, 2021). Devir sayısını takiben ilerleme hızı ve yaklaşma açılarının etkili olduğu görülmektedir. Yine de devir sayısının etkisi ile kıyaslandığında bu parametrelerin motor akımı üzerinde oluşturduğu katkının çok az olduğu göze çarpmaktadır. $\mathrm{P}$ değeri değerlendirildiğinde $95 \%$ güven aralığında devir sayısı, ilerleme hızı ve yaklaşma açılarının önem arz ettiği görülmektedir. İlerleme hızı da talaş kaldırma esnasında bilhassa kesme kuvvetleri üzerinde etkisi olan bir parametredir. $\mathrm{Bu}$ nedenle bu parametredeki değişimin motor akımı üzerinde etkili olduğu düşünülmektedir. $\mathrm{F}$ değerleri incelendiğinde görüleceği üzere devir sayısı en etkili parametre olarak gözükmektedir.

Çalışmada optimizasyon için sinyal gürültü oranına dayalı bir analiz yapılmış ve Taguchi metodu kullanılmıştır. Burada esas amaç değerlendirilen çıktı parametresinden beklentiyi belirlemek ve optimizasyonun minimizasyon ya da maksimizasyon yönünde olacağına karar vermektir. Motor akımının artışı kesme için gerekli gücü artıracağı ve bu da işleme maliyetini doğrudan etkileyeceği için bu parametreyi minimumda tutmak gerekmektedir. $\mathrm{Bu}$ maksatla amaç fonksiyonlarından en küçük olan en iyidir prensibi seçilerek hesaplama yoluna gidilmiştir. Şekil 2'de sinyal gürültü oranı için esas etkiler veri ortalamalarına göre gösterilmiştir. Buna göre sinyal gürültü oranı yüksek olan parametre seviyesi arzu edilen değer olmaktadır. Elde edilen sonuçlara göre değerleri seçildiğinde motor akımının optimum değerinin elde edilebileceği sonucuna ulaşılmaktadır. $\mathrm{Bu}$ sonuç, endüstride yaygın kullanılan bir malzemenin tornalanması sürecinde meydana gelen motor akımı ve buna bağlı belirlenebilecek güç tüketimi üzerinde parametrelerin etkisini belirlemek açısından önemlidir.

Tablo 4. Sinyal Gürültü oranı için varyans analizi sonuçları

\begin{tabular}{c|c|c|c|c|c}
\hline Parametre & SD & KT & OK & F-de. & P.de. \\
\hline Yakl. Aç1. & 1 & 0.05159 & 0.051587 & 10.32 & 0.008 \\
\hline Dev. Say. & 1 & 0.52171 & 0.521710 & 104.38 & 0.000 \\
\hline İler. Hızı & 1 & 0.09018 & 0.090176 & 18.04 & 0.001 \\
\hline Tal. Deri. & 1 & 0.01762 & 0.017618 & 3.52 & 0.087 \\
\hline Hata & 11 & 0.05498 & 0.004998 & - & - \\
\hline Toplam & 15 & 0.73607 & - & - & - \\
\hline
\end{tabular}

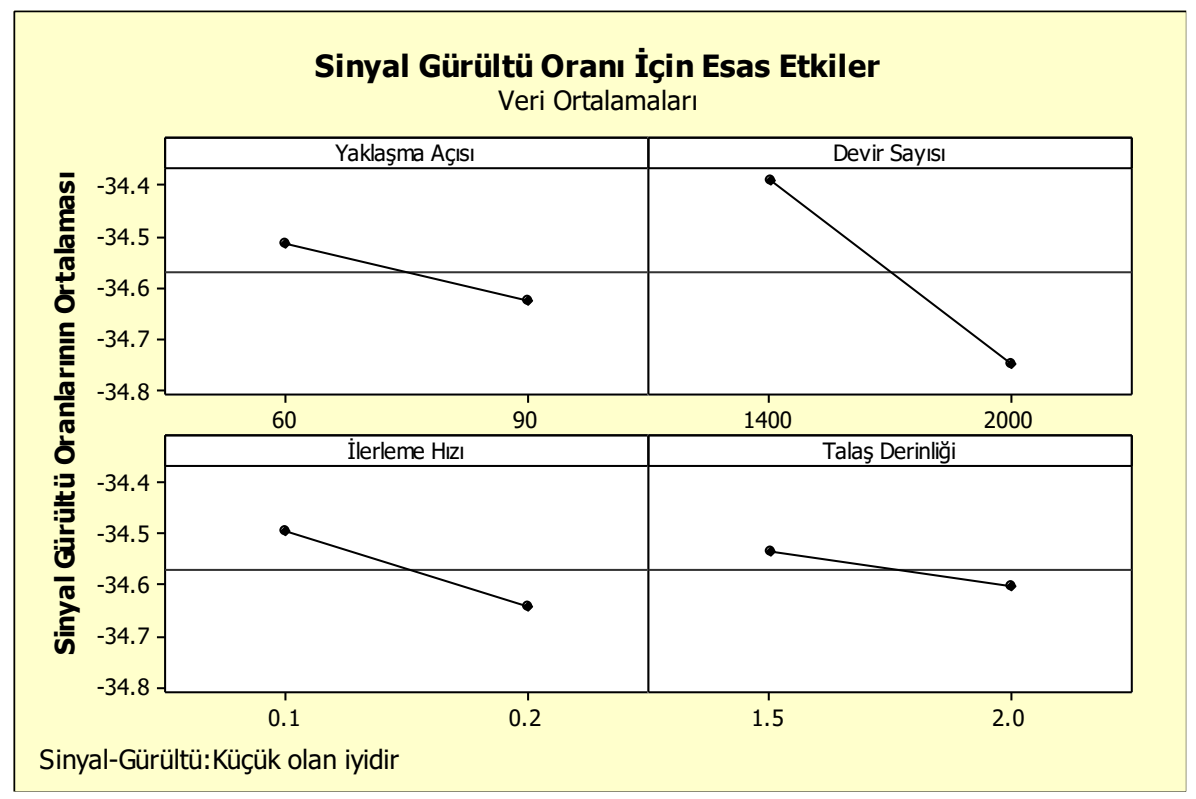

Şekil 2. Sinyal gürültü oranı için en esas etkiler 


\subsection{Akustik Emisyon Analizi ve Optimizasyonu}

Akustik emisyon mikro boyutta çok yüksek frekanslı gerilme dalgası yayılımıdır. Malzemede plastik deformasyon meydana getirecek bir dış kuvvet uygulandığında yüksek frekanslı gerilme dalgası meydana gelmektedir. Bu durum talaşlı imalat işlemlerinde takım temas bölgelerinde aşınmanın oluşması ile başlar ve bu süreçte talaş oluşumu, talaş karışması, talaş kırılması ve takım kırılması gibi olaylarla tetiklenebilmektedir. Akustik emisyon sinyalleri genel olarak iki farklı tipte gözlenmektedir. Aşınma, plastik deformasyon, talaş oluşumu gibi olaylar akustik emisyonda küçük değişimler meydana getirirken, kırılma gibi büyük deformasyona sebep olan olaylar ise büyük değişimlere neden olmaktadır (Kuntoğlu ve ark., 2020; Kuntoğlu ve ark., 2021). Bu sebeple akustik emisyon sinyallerinin çok yüksek değerlere ulaşması arzu edilmez. Akustik emisyon sinyalleri takım kırılmasının tespit edilmesinde oldukça hassastır. Kesme süresince meydana gelen değişimlerin anlık olarak takibinde etkili olarak kullanılabilen akustik emisyon parametrelerinin optimizasyonu ve analizi oldukça önemlidir. $\mathrm{Bu}$ şekilde akustik emisyon verilerinin detaylı analizi yapılarak sinyal üzerindeki etkilerinin tespit edilmesi ani takım kırılmalarının önüne geçilmesi bakımında önem kazanmaktadır.

Tablo 5 sinyal gürültü oranı için varyans analizi sonuçlarını özetlemektedir. Buna göre akustik emisyon üzerinde en etkili parametre devir sayısıdır. Devir sayısının artması kesme kuvvetlerini azaltarak talaş kaldırma işlemini kolaylaştırmaktadır. Talaş kaldırma operasyonu temel olarak bir plastik deformasyon işlemidir. Buradan hareketle artan kesme hızındaki değişime bağlı olarak akustik emisyon sinyallerinin dalgalanmaya maruz kalacağı düşünülmektedir. Yüzde katkı oranı hesaplandığında $89.5 \%$ oranında devir sayısının akustik emisyon üzerinde etkili olduğu görülmektedir. İlerleme hıznın kesme hızını takip ettiği, talaş derinliği ve yaklaşma açısının çok az bir etkiye sahip olduğu görülmektedir. P değerlerine bakıldığında her iki parametrenin $95 \%$ güven aralığında olduğu anlaşılmaktadır. F değerlerine bakıldığında P değeri yüzde katkı değerleri ile uyumlu sonuçlar verdiği görülmektedir.

Optimizasyon yaklaşımı Taguchi metodu ile gerçekleştirilmiştir. Şekil 3 'te sinyal gürültü oranı için en esas etkiler gösterilmiştir. Sinyal gürültü oranı kullanılarak en küçük en iyidir prensibi uyarınca hesaplama yapılmıştır. Sonuçlara göre $\mathrm{v}_{1}=1400 \mathrm{dev} / \mathrm{dak}, \mathrm{f}_{1}=0.1 \mathrm{~mm} / \mathrm{dev}, \mathrm{d}_{2}=2 \mathrm{~mm}, \kappa_{2}=90^{\circ}$ parametreleri seçildiğinde akustik emisyonun minimize edilebildiği görülmektedir. Yüksek devir sayısında malzeme deformasyon hızının artmasına bağlı olarak akustik emisyonun arttığı düşünülmektedir. Benzer bir etkiyi daha az olacak şekilde ilerleme hızı da yapmaktadır. Talaş derinliği ve yaklaşma açısı parametre seviyeleri arasında ihmal edilebilecek bir fark olduğu görülmektedir.

Tablo 5 Sinyal Gürültü oranı için varyans analizi sonuçları

\begin{tabular}{c|c|c|c|c|c}
\hline Parametre & SD & KT & OK & F-değeri & P-değeri \\
\hline Yaklaşma Açısı & 1 & 0.0029 & 0.0029 & 0.05 & 0.831 \\
\hline Devir Sayısı & 1 & 14.5949 & 14.5949 & 0.000 \\
\hline İlerleme Hızı & 1 & 1.0095 & 1.0095 & 0.002 \\
\hline Talaş Derinliği & 1 & 0.0228 & 0.0228 & 0.38 & - \\
\hline Hata & 11 & 0.6669 & 0.0606 & - \\
\hline Toplam & 15 & 16.2970 & - & - \\
\hline
\end{tabular}




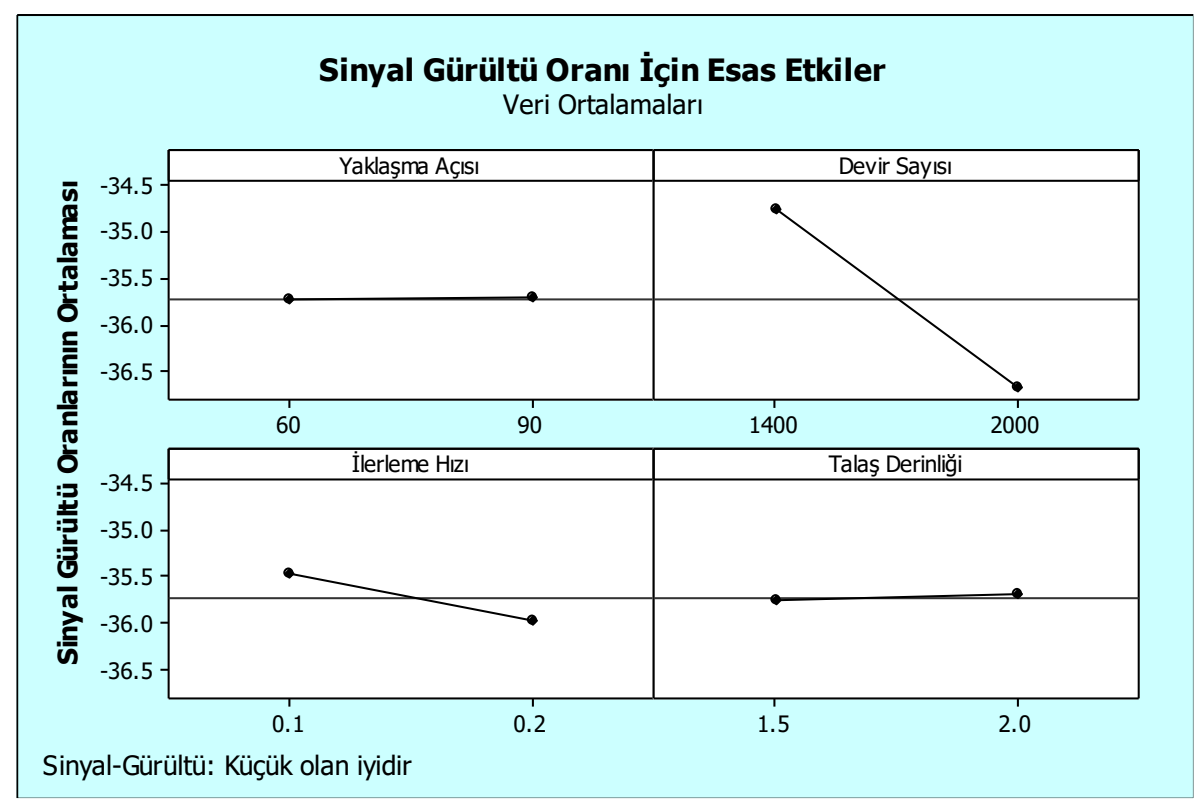

Şekil 3. Sinyal gürültü oranı için en esas etkiler

\section{Sonuç}

$\mathrm{Bu}$ çalışmada talaşlı imalat işlemlerinden biri olan tornalamada endüstriyel çalışmalarda sıklıkla tercih edilen AISI 5140 malzemenin işlenmesi süresince toplanan motor akımı ve akustik emisyon sinyallerinin ölçümü, değerlendirilmesi ve optimizasyonu gerçekleştirilmiştir. Akustik emisyon ve motor akımı talaş kaldırma esnasında işlem hakkında önemli bilgi kaynağı olarak kullanılabilen çıktılardır. Bununla beraber diğer işlenebilirlik kriterleri kadar çok çalışma olmadığı görülmektedir. Literatüre bakıldığında bu sensörlere dayalı imalat işlemlerinin oldukça önemli bilgi kaynağı olduğu gözlenmektedir. Bu kapsamda çalışma spesifik bir malzemenin tornalanması sürecinde motor akımı ve akustik emisyon verilerini ele alması bakımından ilk olma özelliği taşımaktadır. Çalışma sonucunda yapılan çıkarımlar şu şekilde sıralanabilir:

1. Motor akımı işleme esnasında harcanan gücün hesaplanmasında önemli bir veri kaynağıdır. Tornalama süresince devir sayısının motor akımı üzerinde en etkili parametre olduğu görülmüştür (70.8\%). İlerleme hızı ve yaklaşma açısının istatistiksel olarak önemli olduğu P değeri yardımı ile görülse de katkı değeri bakımından kesme hızına kıyasla çok küçük bir etkilerinin olduğu tespit edilmiştir.

2. Taguchi sinyal gürültü oranı ile hesaplanan sonuçlara göre $\mathrm{v}_{1}=1400 \mathrm{dev} / \mathrm{dak}, \mathrm{f}_{1}=0.1 \mathrm{~mm} / \mathrm{dev}, \mathrm{d}_{1}=1.5 \mathrm{~mm}$ ve $\kappa_{1}=60^{\circ}$ değerleri seçildiğinde optimum motor akımı değerinin elde edilebileceği görülmüştür.

3. Akustik emisyon malzemede mikro boyutta plastik deformasyon, kırılma, çatlak, sürünme, talaşlı imalat penceresinden bakıldığında ise talaş karışması, kırılması, takım kırılması gibi etkileri çok hassas olarak ölçmeyi sağlayan bir sensör verisi olarak öne çıkmaktadır.
4. Optimizasyon sonuçlarına göre akustik emisyon minimizasyonu için seçilmesi gereken kesme parametreleri $\mathrm{v}_{1}=1400 \mathrm{dev} / \mathrm{dak}, \mathrm{f}_{1}=0.1 \mathrm{~mm} / \mathrm{dev}, \mathrm{d}_{2}=$ $2 \mathrm{~mm}, \kappa_{2}=90^{\circ}$ şeklindedir.

\section{Kaynakça}

Acar, O., Sağlam, H. ve Şaka, Z., 2021, Measuring Curvature of Trajectory Traced by Coupler of An Optimal Four-Link Spherical Mechanism, Measurement, 109189.

Ahmed, Y. S., Alam, M. S., Arif, A. ve Veldhuis, S., 2019, Use of acoustic emission and cutting force signals to monitor built-up edge formation in stainless steel turning, The International Journal of Advanced Manufacturing Technology, 103 (5), 2257-2276.

Al-Habaibeh, A. ve Gindy, N., 2000, A new approach for systematic design of condition monitoring systems for milling processes, Journal of materials processing technology, 107 (1-3), 243-251.

Aslan, A., Salur, E., Gunes, A., Sahin, O., Karadag, H. ve Akdemir, A., 2019, The mechanical properties of composite materials recycled from waste metallic chips under different pressures, International Journal of Environmental Science and Technology, 16 (9), 52595266.

Aslan, A., 2020, Optimization and analysis of process parameters for flank wear, cutting forces and vibration in turning of AISI 5140: A comprehensive study, Measurement, 163, 107959.

Başaltın, M. ve Yaman, K., 2016, Tornalamada Takım Yanak Aşınmasının Akustik Emisyon (AE) Yöntemiyle Analizi,1st international Mediterranean Science and Engineering Congress,2138-2138,ID:65.

Bhuiyan, M., Choudhury, I. ve Nukman, Y., 2012, Tool condition monitoring using acoustic emission and vibration signature in turning, Proceedings of the world congress on engineering, 1-5. 
Bhuiyan, M., Choudhury, I. A., Dahari, M., Nukman, Y. ve Dawal, S., 2016, Application of acoustic emission sensor to investigate the frequency of tool wear and plastic deformation in tool condition monitoring, Measurement, 92, 208-217.

Chen, X. ve Li, B., 2007, Acoustic emission method for tool condition monitoring based on wavelet analysis, The International Journal of Advanced Manufacturing Technology, 33 (9-10), 968-976.

Chethan, Y., Ravindra, H. ve Krishnegowda, Y., 2019, Optimization of machining parameters in turning Nimonic-75 using machine vision and acoustic emission signals by Taguchi technique, Measurement, 144, 144-154.

Fadare, D., Bonney, J. ve Ezugwu, E., 2012, Influence of cutting parameters and tool wear on acoustic emission signal in high-speed turning of Ti-6Al-4V Alloy, Journal of Emerging Trends in Engineering and Applied Sciences, 3 (3), 547-555.

Jemielniak, K., Kwiatkowski, L. ve Wrzosek, P., 1998, Diagnosis of tool wear based on cutting forces and acoustic emission measures as inputs to a neural network, Journal of Intelligent Manufacturing, 9 (5), 447-455.

Kuntoğlu, M. ve Sağlam, H., 2019, Investigation of progressive tool wear for determining of optimized machining parameters in turning, Measurement, 140, 427-436.

Kuntoğlu, M., Aslan, A., Sağlam, H., Pimenov, D. Y., Giasin, K. ve Mikolajczyk, T., 2020, Optimization and analysis of surface roughness, flank wear and 5 different sensorial data via Tool Condition Monitoring System in turning of AISI 5140, Sensors, 20 (16), 4377.

Kuntoğlu, M. ve Sağlam, H., 2020, Investigation of Signal Behaviors for Sensor Fusion with Tool Condition Monitoring System in Turning, Measurement, 108582.

Kuntoğlu, M., Aslan, A., Pimenov, D. Y., Usca, Ü. A., Salur, E., Gupta, M. K., Mikolajczyk, T., Giasin, K., Kapłonek, W. ve Sharma, S., 2021, A Review of Indirect Tool Condition Monitoring Systems and Decision-Making Methods in Turning: Critical Analysis and Trends, Sensors, 21 (1), 108.

Kuntoğlu, M. ve Aslan, A., 2021

AISI 5140 Çeliğinin Tornalanması Esnasında Yaklaşma Açısı ve Kesme Parametrelerinin İşlenebilirliğe Etkisinin İncelenmesi, Politeknik Dergisi, 1-1.

Li, X., 2002, A brief review: acoustic emission method for tool wear monitoring during turning, International Journal of Machine Tools and Manufacture, 42 (2), 157-165.

Li, X., 2005, Development of current sensor for cutting force measurement in turning, IEEE Transactions on Instrumentation and Measurement, 54 (1), 289-296.

Pimenov, D. Y., Hassui, A., Wojciechowski, S., Mia, M., Magri, A., Suyama, D. I., Bustillo, A., Krolczyk, G. ve Gupta, M. K., 2019, Effect of the relative position of the face milling tool towards the workpiece on machined surface roughness and milling dynamics, Applied Sciences, 9 (5), 842.

Salur, E., Aslan, A., Kuntoglu, M., Gunes, A. ve Sahin, O. S., 2019, Experimental study and analysis of machinability characteristics of metal matrix composites during drilling, Composites Part B: Engineering, 166, 401413.
Salur, E., Acarer, M. ve Şavkliyildiz, İ., 2021, Improving mechanical properties of nano-sized $\mathrm{TiC}$ particle reinforced AA7075 Al alloy composites produced by ball milling and hot pressing, Materials Today Communications, 102202.

Sap, E., 2020, Microstructural and Mechanical Properties of $\mathrm{Cu}$ Based Co-Mo-Reinforced Composites Produced by the Powder Metallurgy Method, Journal of Materials Engineering and Performance, 29 (12), 8461-8472.

Sharma, V. S., Sharma, S. ve Sharma, A. K., 2008, Cutting tool wear estimation for turning, Journal of Intelligent Manufacturing, 19 (1), 99-108.

Şap, E., 2021, Güçlendirilmiş Bakır Esaslı Kompozit Malzemelerin Mikroyapı ve Sertlik Özellikleri, I $\breve{g} d ı r$ Üniversitesi Fen Bilimleri Enstitüsü Dergisi, 11 (1), 590-598.

Tönshoff, H., Jung, M., Männel, S. ve Rietz, W., 2000, Using acoustic emission signals for monitoring of production processes, Ultrasonics, 37 (10), 681-686.

Uzun, M., Munis, M. M. ve Usca, U., 2018, Different ratios CrC particle-reinforced $\mathrm{Cu}$ matrix composite materials and investigation of wear performance, Journal of Engineering Research and Application, 8 (7), 1-7.

Uzun, M. ve Usca, U. A., 2018, Effect of $\mathrm{Cr}$ particulate reinforcements in different ratios on wear performance and mechanical properties of $\mathrm{Cu}$ matrix composites, Journal of the Brazilian Society of Mechanical Sciences and Engineering, 40 (4), 1-9. 